\title{
The impact of different navigation speeds on cybersickness and stress level in VR
}

\begin{abstract}
The aim of this research was to determine if the speed of movement in virtual environments has an impact on cybersickness as potentially experienced by an end user of the system. Cybersickness is a common side effect in virtual reality (VR) systems, shown to have a negative influence on user experience. It can be described as a mismatch between vestibular and oculomotor sensors, where a person has a feeling of movement even though there is none. In this research, we study the impact of different navigation speeds in VR on cybersickness, relying on both subjective ratings indicating cybersickness symptoms, and objective measures of stress level. We wanted to find out if there is a correlation between objective and subjective metrics used. For test purposes, we used the HTC Vive VR headset and scenery from the Talos Principle VR game (where subjects can easily shift between three different movement speeds). Subjective ratings were collected using a questionnaire involving 11 questions used to evaluate cybersickness symptoms. Objective metrics were collected using the Pip Biosensor. A total of 28 participants took part in the study, while 2 participants withdrew due to physical discomfort. Results obtained from the Pip device show no statistically significant difference between navigation speeds for relaxed, stressed, and steady states. Some statistically significant correlations were found between gender and stomach ache, need to vomit, and physical discomfort while wearing HMD. Furthermore, correlation was found between age and variables of nausea in transport vehicles and vertigo. Other correlations found are described in the results section of the paper.
\end{abstract}

\author{
Ana Agić ${ }^{1}$ (i) \\ Ella Murseli ${ }^{1}$ \\ Lidija Mandić ${ }^{1}$ \\ Lea Skorin - Kapov ${ }^{2}$ \\ ${ }^{1}$ University of Zagreb, Faculty of \\ Graphic Arts, Croatia \\ ${ }^{2}$ University of Zagreb, Faculty \\ of Electrical Eingeneering and \\ computing, Croatia
}

Corresponding author:

Ana Agić

e-mail:ana.agic@grf.hr

First recieved: 2.10.2019.

Accepted: 20.12.2019.

\section{KEY WORDS}

Virtual reality, subjective and objective assessment, navigation speed, cybersickness

\section{Introduction}

Navigation (or locomotion) techniques refer to the way in which users move within Virtual Reality (VR) environments. A well-known negative side effect of movement in VR is known as cybersickness, which is manifested as a physical feeling of nausea, headache, dizziness and sweating (Rebenitsch \& Owen, 2016).

This nauseogenic state can be explained as a mismatch between vestibular and oculomotor sensors, meaning that a person perceives movement even though he or she is not actually moving in real space (Golding, 2006). This sensation of illusory movement is known as vection (Keshavarz et al., 2015b; McCauley \& Sharkey, 1992). A common example is that of a person sitting on a train and another train starts to move, causing the person to become confused as to which train is actually moving.

When immersed in VR, one can often sense these cybersickness symptoms. Lawson stated that between $61 \%$ and $80 \%$ of participants experience negative symptoms (Kelly \& Stanney, 2015; Palmisano et al., 2017). It 
was found that the following factors can have a negative effect on VR experience: low resolution, narrow FOV (field of view), extended duration of immersion, habituation, age, susceptibility to motion sickness, and speed of movement (Rebenitsch, 2015; Wang \& Suh, 2019). Many of these factors have been investigated in research papers, often by using various questionnaires for obtaining subjective metrics, and equipment for assessing a participant's objective measures such as heart rate, electrocardiogram, and skin conductance devices (Baumgartner et al., 2006; Dennison et al., 2016; Egan et al., 2016; Keshavarz et al., 2015a). A review paper by Brion and Pumudu (2018) provides a chronicle of research papers which use subjective and/or objective metrics to evaluate and create some form of prediction of cybersickness (Brion \& Pumudu, 2018). However, few papers have explicitly addressed the impact of navigation speed on cybersickness and stress level in VR (Medeiros et al., 2016; So et al., 2001). In their research on navigation speed, So, Lo, and Ho (2001) discuss results which showed that vection and sickness increase with users moving up to a speed of $10 \mathrm{~m} / \mathrm{s}$ in a VR environment. After that, as speed increases up to $59 \mathrm{~m} / \mathrm{s}$, speed symptoms were found to stabilize, with an ANOVA analysis showing no significant interaction between speed and nauseogenic symptoms, as is in-line with previous findings. In this paper, we present the results of a subjective study aimed at investigating the impact of different navigation speeds in VR on cybersickness, relying on both subjective ratings and objective measures of stress level.

\section{Methodology}

For the purpose of testing the influence of different navigation speeds, we used the game "The Talos Principle VR", developed by Croatian game development team "Croteam" (Croteam, 2017). This is a puzzle-based game, originally developed for PCs and later adapted for VR systems. In the game options, the menu enables users to easily switch between two navigation methods, each with variations: 1) two types of "teleportation", and 2) the "classic" type, also referred as "hover" or "sliding" method. We used this "classic" method since it has three different speeds of movement ("slow": 4.25 $\mathrm{m} / \mathrm{s}$, "medium": $6.37 \mathrm{~m} / \mathrm{s}$, and "fast": $8.5 \mathrm{~m} / \mathrm{s}$;). Figure 1. depicts the scenery of Talos Principle VR. Tests were conducted in a laboratory environment, with the HTC Vive VR headset and its corresponding controllers used. HTC Vive is a commercial device, with $2160 \times 1200$ resolution (1080 x 1200 per eye), horizontal FOV of $100^{\circ}$, and $110^{\circ}$ vertical field of view. The game is originally intended as a logic game where players have to solve puzzles to unlock levels, but in our case, they were instructed to only move freely around the presented scenery, given that the focus was on investigating navigation speeds. Since users can move within the VR environment with only one controller, the other hand was available for the Pip biosensor stress measuring device. The Pip biosensor (see Figure 2) detects variations of electrodermal activity, and uses a proprietary algorithm to give numerical results indicating the number of relaxed, steady, and stressed situations via galvanic skin response measurement, approximately 8 times per second (Egan et al., 2016). The Pip device is held by the user in their hand with index finger and thumb.

The test procedure was as follows: first, the participant was seated, and their current level of stress was recorded with the Pip biosensor during a 2-minute time interval. The person was then asked general questions regarding their age, gender, and previous experience with VR. Afterwards, they were familiarized with the VR headset, and shown how to use the controllers to

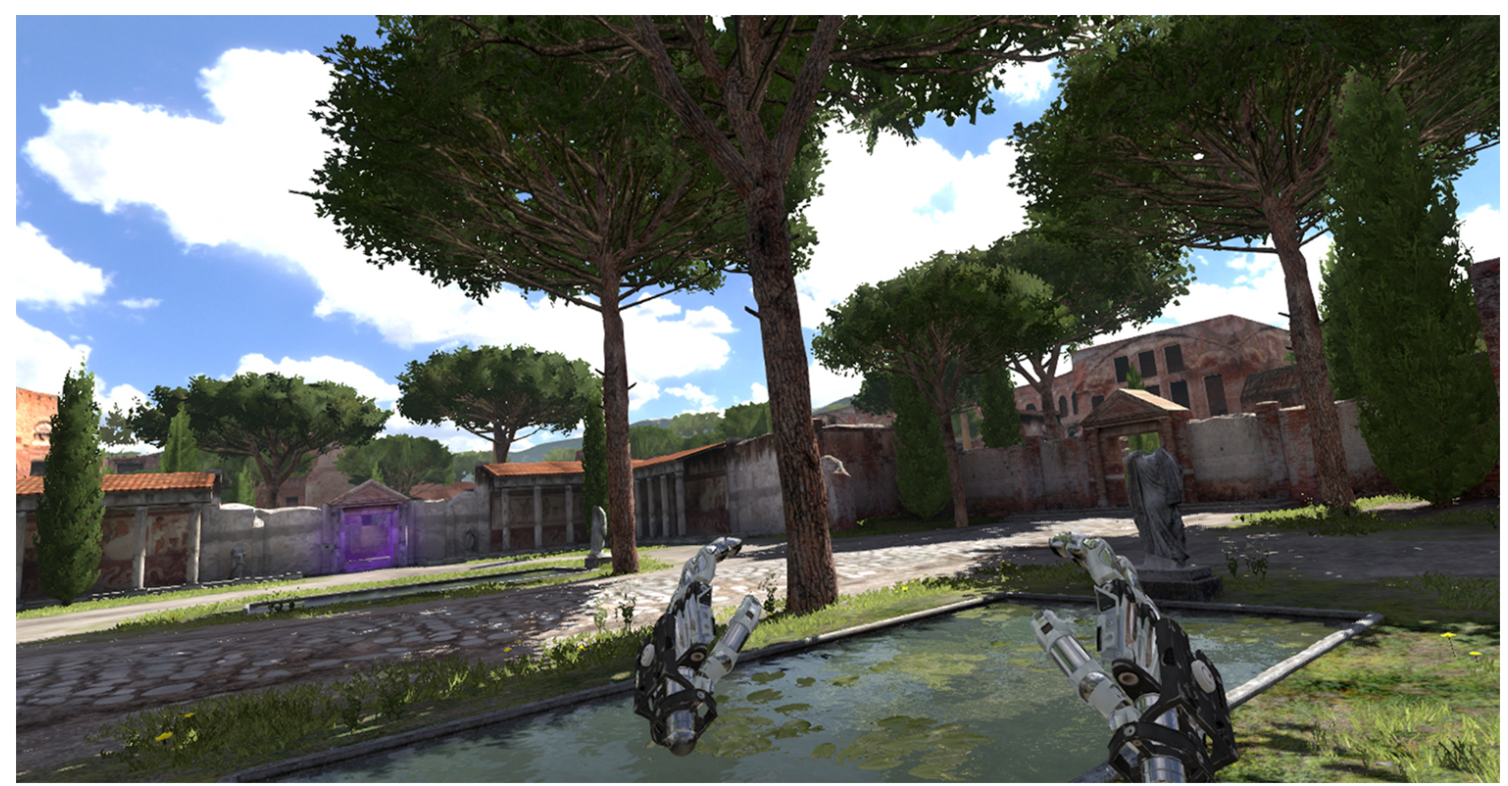

» Figure 1: Scenery of the Talos Principle VR game 
move in the system. Testing was carried out in such a way that the participant held the HTC Vive controller in one hand, and the Pip device in the other hand. Upon completing 2 minutes of free movement, the participant was asked questions related to cybersickness symptoms. The administrator recorded answers while the participants were still immersed in the VR environment, so that they did not need to take the headset on and off. In the same manner, each participant completed the survey after trying the other two locomotion speeds. The order of speed movements was randomized for every participant. The total test procedure lasted approximately 15 minutes per participant (which included a short introduction to VR, measurement of stress before immersion in VR, testing the movement speeds, and questionnaires). The immersion in VR and speed testing was about 9 minutes (three speeds, each tested for 2 minutes + answering questionnaires).

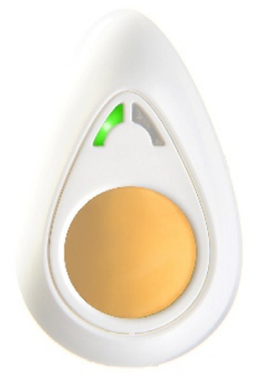

» Figure 2: The Pip biosensor

A total of 30 participants took part in this study, and 2 withdrew due to discomfort, leaving a total of 28 participants, of which 15 were females and 13 males, between the ages of 19 and 58 (median age was 21). For most participants, this was their first experience with VR. The questionnaire included 11 questions regarding subjective experience, used to evaluate cybersickness symptoms. The questionnaire is based on Kennedy's Simulator Sickness Questionnaire (SSQ) (Kennedy et al., 1993), which originally contains 16 questions, and these symptoms are placed into three categories (nausea, oculomotor, and disorientation symptoms). It is important to mention that Kennedy's questionairre is used for assesing sickness while using flight simulators, which differs slightly when compared to cybersickness (Stanney et al., 1997). Kenne$d y$ 's questionairre was thus modified so that only 11 out of 16 questions were used. His questionairre has a few additional questions, such as general discomfort, fatigue (which we expand to "fatigue in VR"), incresed salivation, difficulty concentrating, fullness of head, dizzy (eyes open/eyes closed), stomach awareness (we modified to "need to vomit"), and burping. There are other surveys which can be used for assesing cybersickness, one of the oldest being the Pensacola Motion Sickness Questionaire (MSQ) (Davis et al., 2014; Kennedy et al., 1993). Short Symptoms Checklist by (Nichols et al., 1997) also relies on SSQ, and comprises 6 symptoms (2 taken from oculomotor, 2 from nausea, and 2 from disorientation), aiming to be easily applied while a user is still immersed in the VR environment. To evaluate subjective experience in VR, specifically the feeling of presence, a questionairre by (Witmer \& Singer, 1998) is often used. The SUS (Slater-Usoh-Steed) questionairre can be mentioned as an example, where they examine the sense of being present in the surrounding space (Usoh et al., 2000). Presence and cybersickness are frequently researched issues in VR, and according to a review paper from (Weech et al., 2019), increasing presence could reduce cybersickness.

In our questionairre, all questions used a 5 point Likert scale from 1 (strongly disagree) to 5 (strongly agree). Participants were asked the following: Do you feel: vertigo, blurred vision, difficulty to focus on objects, a headache, sweating, stomach ache, need to vomit, eye strain, fatigue, and physical discomfort while wearing a headset? The last question was to select which of the symptoms was the most dominant, given that we wanted to determine if some or any of symptoms would be remembered as most prominent/dominant for each participant. After completing all three movement speeds, participants were asked to determine which speed made them feel the least comfortable and which made them feel the most comfortable. A dataset including all test results is made open at request, available at: ana.agic@grf.hr.

\section{Results and discussion}

Results were obtained by using the IBM SPSS 23.0 statistical program. Since the Shapiro-Wilk test showed that variables used in the research significantly deviate from the Gaussian curve, non-parametric statistical procedures were used in processing of the data with basic descriptive statistics. The Friedman test was used to test the differences between dependent groups of subjects. We then used Spearman's correlation test for testing correlation between ordinal variables, and Kendall Tau-b for testing correlation between ordinal and nominal variables. Statistical significance was set at $p<0.05$. From the 28 participants, 18 (64.3\%) had no prior experience in VR, 9 (32.1\%) use VR several times per year, and 1 participant (3.6\%) stated usage of VR once per week. As for experiencing sickness in transport vehicles, 3 (10.7\%) participants feel transport sickness in adulthood while the rest do not, 25 (89.3\%)). Moreover, participants were asked if they had experienced nausea in transport vehicles while they were children, 12 (42.9\%) stated yes, while 16 (57.1\%) stated no. 10 (35.7\%) participants have corrected to normal vision, and 18 (64.3\%) have normal vision.

The last question in the questionnaire was to determine the dominant symptom among all symptoms asked. Our goal was to examine if some symptoms are more noticeable after completing every movement speed. The percentages of dominant symptoms are presented in Fig. 3 for all three movement speeds. It can be noticed that 
the most commonly chosen dominant symptom is vertigo, experienced in fast movement speed (10 participants, $(35.7 \%))$, followed by medium speed (9 participants, (32.1\%)) and lastly slowest speed with 5 participants (17.9\%). The second interesting dominant symptom is blurred vision, which yielded the same score for slow and medium speed (9 participants (32.1\%)), and interestingly, a lower score for the fastest speed (4 participants $(14.3 \%))$. Sweating is also interesting, with the fastest speed yielding the highest score (5 participants (17.9\%)), followed by the slowest speed (4 participants (14.3\%)).

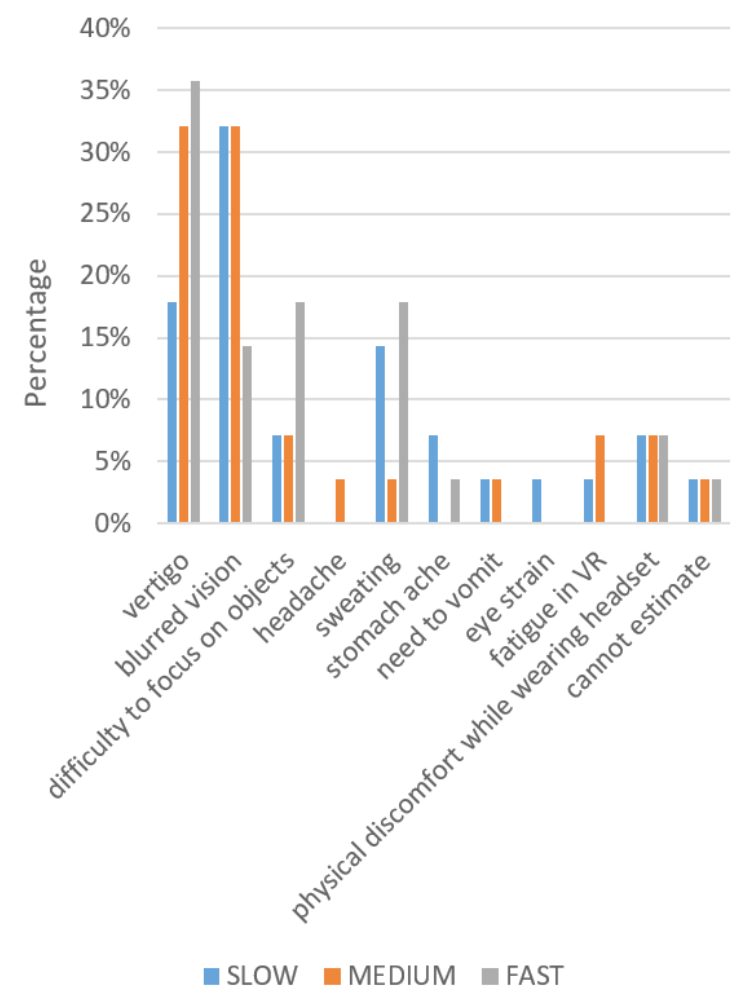

» Figure 3: Percentage of participants indicating a given symptom as "dominant", across all three tested speeds

Regarding questions about highest/lowest discomfort level after completing all three speeds, results shown in Fig. 4 show that the lowest discomfort level was experienced by the most participants at medium speed (12 participants (42.9\%)), followed by fast and slowest speed. The highest discomfort level was experienced by the most participants at fastest speed, (12 participants (42.9\%)) as was expected, followed by slow and medium movement speed.

Table 1 portrays the statistical difference for variables tested across all three speeds, for all participants $(n=28)$. Variables did not show any statistically relevant difference between the observed moving speeds. Table 2 shows the results from the Pip biosensor, median, and standard deviation for all participants $(n=28)$, which did not yield any statistically relevant results, neither between all three measured states, nor in relation to the neutral state.

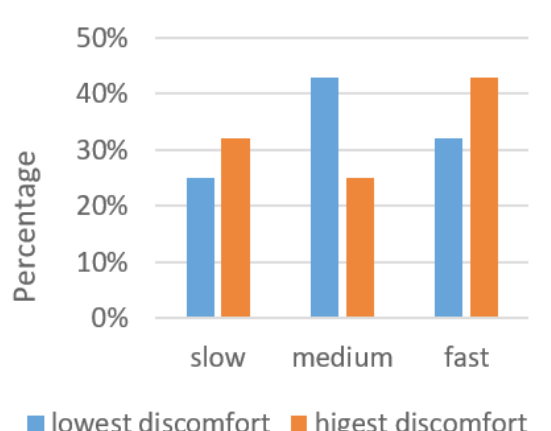

» Figure 4: Highest and lowest discomfort levels related to speed of movement

\section{Table 1}

Statistical difference between variables tested in the given questionnaire for all 3 speeds

\begin{tabular}{|c|c|c|c|c|c|}
\hline & SLOW & MEDIUM & FAST & & \\
\hline & $\mathrm{M}$ & $\mathrm{M}$ & $\mathrm{M}$ & $\mathrm{Fr}_{\mathrm{r}}$ & $\mathrm{p}$ \\
\hline Vertigo & 1.5 & 2 & 2 & 2.493 & .287 \\
\hline Blurred vision & 2 & 2 & 2 & 1.143 & .565 \\
\hline $\begin{array}{l}\text { Difficulty to focus } \\
\text { on objects }\end{array}$ & 1.5 & 1 & 1.5 & 5.600 & .061 \\
\hline Headache & 1 & 1 & 1 & 5.429 & .066 \\
\hline Sweating & 2 & 2 & 2 & 0.520 & .771 \\
\hline Stomach ache & 1 & 1 & 1 & 0.692 & .707 \\
\hline Need to vomit & 1 & 1 & 1 & 1.000 & .607 \\
\hline Eye strain & 1.5 & 2 & 2 & 0.304 & .859 \\
\hline Fatigue in VR & 1 & 2 & 1 & 0.383 & .826 \\
\hline $\begin{array}{l}\text { Physical discomfort } \\
\text { while wearing headset }\end{array}$ & 1.5 & 2 & 2 & 1.167 & .558 \\
\hline
\end{tabular}

\section{Table 2}

PIP BIOSENSOR statistical results for all measured states

\begin{tabular}{l|c|c|c|c|c|c}
\hline & NEUTRAL & SLOW & MEDIUM & FAST & & \\
\hline & $\mathrm{M}$ & $\mathrm{M}$ & $\mathrm{M}$ & $\mathrm{M}$ & $\mathrm{F}_{\mathrm{r}}$ & $\mathrm{p}$ \\
\hline Stress & 20 & 17.5 & 20 & 18 & 5.834 & .120 \\
\hline Steady & 17 & 18 & 20.5 & 16 & 3.520 & .318 \\
\hline Relaxed & 14.5 & 20 & 16.5 & 18.5 & 4.115 & .249 \\
\hline
\end{tabular}

Spearman's correlation test was performed between all the ordinal variables of slow, medium, and fast speed, respectively, and objective measures from the Pip stress measurement device. For nominal and ordinal variables, the Kendall Tau-b correlation method was used. Table 3 presents correlations described in this section. Variables with no correlations are not in the tables (such as sweating). Bolded values in the table indicate significant correlations. We found weak to moderate positive correlation between gender and physical discomfort while wearing HMD in slow $(r=0.489, p=0.006)$, medium ( $r=$ $0.504, p=0.005)$ and fast speed $(r=0.394, p=0.027)$, and between gender and stomach ache $(r=0.374, p=0.049)$ and need to vomit in fast speed $(r=0.374, p=0.049)$. There is moderate positive correlation between age and 
nausea in transport vehicles ( $r=0.448, p=0.008)$, which would indicate that nausea increases with age. We can observe weak to moderate positive correlation between age and vertigo in fast speed $(r=0.458, p=0.014)$, need to vomit in slow $(r=0.388, p=0.041)$ and medium speed $(r=0.412, p=0.029)$, but not in fast speed. Moreover, frequency of usage (of VR technology) showed several weak to moderate positive correlations between medium speed of movement and: stomach ache $(r=0.493$, $p=0.007)$, need to vomit ( $r=0.427, p=0.022)$, physical discomfort while wearing HMD $(r=0.370, p=0.035)$ and the number of stress events $(r=0.326, p=0.045)$. Frequency of usage and headache showed positive correlation in fast speed $(r=0.450, p=0.017)$. As for nausea in transport vehicles, one weak positive correlation was found with need to vomit variable $(r=0.413, p=0.03)$. Lastly, nausea in transport vehicles as a child shows negative, but still significant correlation in slow $(r=$ $-0.389, p=0.028)$ and fast speed $(r=-0.392, p=0.027)$ with blurred vision, and with difficulty to focus on objects at fast speed $(r=-0.376, p=0.035)$. Nausea in transport vehicles as a child and vertigo variable showed weak but positive correlation ( $r=0.357, p=0.047)$, which indicates that adults who experienced nausea in transport vehicles as children are more prone to vertigo in virtual reality.

Finally, correlations between highest and lowest discomfort regarding speed in relation to variables were found. It can be observed that highest discomfort regarding speed has a weak positive correlation to stomach ache in medium speed ( $r=0.452, p=0.016)$, and we can observe weak negative correlation in lowest discomfort regarding medium speed also with stomach ache $(r=-0.391, p=0.040)$.

Highest discomfort regarding speed is correlated with fatigue in VR at medium speed $(r=-0.468, p=0.012)$, and physical discomfort while wearing the HMD $(r=0.407$, $\mathrm{p}=0.032$ ). Correlations with fast speed and highest discomfort were found for vertigo $(r=0.473, p=0.011)$, stomach ache $(r=0.432, p=0.022)$ and need to vomit $(r=0.432, p=0.022)$ variables.

\section{Table 3}

Correlations between variables in all 3 speeds

\begin{tabular}{|c|c|c|c|c|c|c|c|c|c|c|}
\hline & $\begin{array}{c}\text { nausea in } \\
\text { transport } \\
\text { vehicles }\end{array}$ & vertigo & $\begin{array}{l}\text { blurred } \\
\text { vision }\end{array}$ & $\begin{array}{c}\text { difficulty } \\
\text { to focus on } \\
\text { objects }\end{array}$ & headache & $\begin{array}{l}\text { stomach } \\
\text { ache }\end{array}$ & $\begin{array}{l}\text { need to } \\
\text { vomit }\end{array}$ & $\begin{array}{l}\text { fatigue } \\
\text { in VR }\end{array}$ & $\begin{array}{c}\text { physical } \\
\text { discomfort } \\
\text { while } \\
\text { wearing HMD }\end{array}$ & $\begin{array}{l}\text { stress } \\
\text { events }\end{array}$ \\
\hline \multirow[t]{3}{*}{ Gender } & & $\begin{array}{l}\text { S:-0.146 } \\
0.429\end{array}$ & $\begin{array}{l}\text { S: } 0.283 \\
0.110\end{array}$ & $\begin{array}{l}\text { S:-0.044 } \\
0.804\end{array}$ & $\begin{array}{l}\text { S: } 0.133 \\
0.479\end{array}$ & $\begin{array}{l}\text { S:-0.209 } \\
0.272\end{array}$ & $\begin{array}{l}\text { S: } 0.256 \\
0.180\end{array}$ & $\begin{array}{l}\text { S: } 0.067 \\
0.706\end{array}$ & $\begin{array}{l}\text { S: } 0.489 * * \\
0.006\end{array}$ & $\begin{array}{l}\text { S: } 0.011 \\
0.945\end{array}$ \\
\hline & & $\begin{array}{l}\text { M: } 0.071 \\
0.693\end{array}$ & $\begin{array}{l}\text { M: } 0.203 \\
0.261\end{array}$ & $\begin{array}{l}\text { M: } 0.028 \\
0.877\end{array}$ & $\begin{array}{l}\text { M: } 0.278 \\
0.139\end{array}$ & $\begin{array}{l}\text { M: } 0.317 \\
0.089\end{array}$ & $\begin{array}{l}\text { M: } 0.249 \\
0.189\end{array}$ & $\begin{array}{l}\text { M: } 0.191 \\
0.289\end{array}$ & $\begin{array}{l}\text { M: } 0.504 * * \\
0.005\end{array}$ & $\begin{array}{l}\text { M: } 0.076 \\
0.643\end{array}$ \\
\hline & & $\begin{array}{l}F: 0.184 \\
0.297\end{array}$ & $\begin{array}{l}F: 0.269 \\
0.129\end{array}$ & $\begin{array}{l}F: 0.089 \\
0.619\end{array}$ & $\begin{array}{l}F:-0.010 \\
0.959\end{array}$ & $\begin{array}{l}\text { F: } 0.374^{*} \\
0.049\end{array}$ & $\begin{array}{l}\text { F: } 0.374 * \\
0.049\end{array}$ & $\begin{array}{l}F: 0.161 \\
0.369\end{array}$ & $\begin{array}{l}\text { F: } 0.394^{*} \\
0.027\end{array}$ & $\begin{array}{l}F: 0.079 \\
0.628\end{array}$ \\
\hline \multirow[t]{3}{*}{ Age } & \multirow[t]{3}{*}{$\begin{array}{l}0.448^{* *} \\
0.008\end{array}$} & $\begin{array}{l}\text { S:0.096 } \\
0.626\end{array}$ & $\begin{array}{l}\text { S: } 0.103 \\
0.604\end{array}$ & $\begin{array}{l}\text { S: } 0.084 \\
0.669\end{array}$ & $\begin{array}{l}\text { S: } 0.143 \\
0.469\end{array}$ & $\begin{array}{l}\text { S: } 0.158 \\
0.422\end{array}$ & $\begin{array}{l}\text { S: } 0.388^{*} \\
0.041\end{array}$ & $\begin{array}{l}\text { S: } 0.193 \\
0.324\end{array}$ & $\begin{array}{l}\text { S: } 0.250 \\
0.200\end{array}$ & $\begin{array}{l}\text { S: } 0.366 \\
0.056\end{array}$ \\
\hline & & $\begin{array}{l}\text { M: } 0.191 \\
0.330\end{array}$ & $\begin{array}{l}\text { M: } 0.107 \\
0.587\end{array}$ & $\begin{array}{l}\text { M: } 0.150 \\
0.447\end{array}$ & $\begin{array}{l}\text { M:-0.018 } \\
0.927\end{array}$ & $\begin{array}{l}\text { M: } 0.298 \\
0.123\end{array}$ & $\begin{array}{l}\text { M: } 0.412^{*} \\
0.029\end{array}$ & $\begin{array}{l}M: 0.274 \\
0.158\end{array}$ & $\begin{array}{l}M: 0.230 \\
0.239\end{array}$ & $\begin{array}{l}M: 0.058 \\
0.768\end{array}$ \\
\hline & & $\begin{array}{l}\text { F: } 0.458^{*} \\
0.014\end{array}$ & $\begin{array}{l}F: 0.197 \\
0.315\end{array}$ & $\begin{array}{l}F: 0.062 \\
0.754\end{array}$ & $\begin{array}{l}F: 0.173 \\
0.378\end{array}$ & $\begin{array}{l}F: 0.329 \\
0.087\end{array}$ & $\begin{array}{l}F: 0.343 \\
0.074\end{array}$ & $\begin{array}{l}F: 0.137 \\
0.488\end{array}$ & $\begin{array}{l}F: 0.216 \\
0.269\end{array}$ & $\begin{array}{l}F: 0.076 \\
0.699\end{array}$ \\
\hline \multirow{3}{*}{$\begin{array}{l}\text { How often } \\
\text { do you } \\
\text { use VR }\end{array}$} & & $\begin{array}{l}\text { S: } 0.067 \\
0.713\end{array}$ & $\begin{array}{l}\text { S: } 0.044 \\
0.803\end{array}$ & $\begin{array}{l}\text { S: } 0.054 \\
0.758\end{array}$ & $\begin{array}{l}\text { S: } 0.147 \\
0.426\end{array}$ & $\begin{array}{l}\text { S:-0.102 } \\
0.584\end{array}$ & $\begin{array}{l}\text { S: } 0.060 \\
0.750\end{array}$ & $\begin{array}{l}\text { S: } 0.155 \\
0.377\end{array}$ & $\begin{array}{l}\text { S: } 0.213 \\
0.248\end{array}$ & $\begin{array}{l}\text { S: } 0.280 \\
0.078\end{array}$ \\
\hline & & $\begin{array}{l}M: 0.207 \\
0.242\end{array}$ & $\begin{array}{l}\text { M: } 0.023 \\
0.898\end{array}$ & $\begin{array}{l}\text { M: } 0.067 \\
0.709\end{array}$ & $\begin{array}{l}\text { M: } 0.166 \\
0.380\end{array}$ & $\begin{array}{l}\mathrm{M}: 0.493 * * \\
0.007\end{array}$ & $\begin{array}{l}\text { M: } 0.427^{*} \\
0.022\end{array}$ & $\begin{array}{l}M: 0.338 \\
0.056\end{array}$ & $\begin{array}{l}\text { M: } 0.370^{*} \\
0.035\end{array}$ & $\begin{array}{l}\text { M: } 0.326^{*} \\
0.045\end{array}$ \\
\hline & & $\begin{array}{l}F: 0.009 \\
0.960\end{array}$ & $\begin{array}{l}F:-0.113 \\
0.518\end{array}$ & $\begin{array}{l}F:-0.027 \\
0.878\end{array}$ & $\begin{array}{l}\text { F: } 0.450 * \\
0.017\end{array}$ & $\begin{array}{l}F: 0.351 \\
0.061\end{array}$ & $\begin{array}{l}F: 0.351 \\
0.061\end{array}$ & $\begin{array}{l}F: 0.234 \\
0.186\end{array}$ & $\begin{array}{l}F: 0.240 \\
0.170\end{array}$ & $\begin{array}{l}F: 0.004 \\
0.981\end{array}$ \\
\hline \multirow{3}{*}{$\begin{array}{l}\text { Nausea in } \\
\text { transport } \\
\text { vehicles }\end{array}$} & & $\begin{array}{l}\text { S: } 0.061 \\
0.742\end{array}$ & $\begin{array}{l}\text { S:-0.152 } \\
0.391\end{array}$ & $\begin{array}{l}\text { S:-0.151 } \\
0.400\end{array}$ & $\begin{array}{l}\text { S:-0.175 } \\
0.351\end{array}$ & $\begin{array}{l}\text { S:-0.139 } \\
0.463\end{array}$ & $\begin{array}{l}\text { S: } 0.333 \\
0.081\end{array}$ & $\begin{array}{l}\text { S:-0.283 } \\
0.113\end{array}$ & $\begin{array}{l}\text { S: } 0.115 \\
0.521\end{array}$ & $\begin{array}{l}\text { S: } 0.300 \\
0.063\end{array}$ \\
\hline & & $\begin{array}{l}\text { M: } 0.314 \\
0.080\end{array}$ & $\begin{array}{l}\text { M:-0.153 } \\
0.398\end{array}$ & $\begin{array}{l}\text { M:-0.098 } \\
0.589\end{array}$ & $\begin{array}{l}\text { M:-0.176 } \\
0.350\end{array}$ & $\begin{array}{l}\text { M: } 0.068 \\
0.717\end{array}$ & $\begin{array}{l}\text { M: } 0.413 * \\
0.030\end{array}$ & $\begin{array}{l}M:-0.021 \\
0.905\end{array}$ & $\begin{array}{l}M: 0.084 \\
0.637\end{array}$ & $\begin{array}{l}\text { M: } 0.031 \\
0.852\end{array}$ \\
\hline & & $\begin{array}{l}F: 0.062 \\
0.725\end{array}$ & $\begin{array}{l}F:-0.007 \\
0.969\end{array}$ & $\begin{array}{l}F:-0.150 \\
0.400\end{array}$ & $\begin{array}{l}F: 0.365 \\
0.056\end{array}$ & $\begin{array}{l}F: 0.151 \\
0.427\end{array}$ & $\begin{array}{l}F: 0.174 \\
0.359\end{array}$ & $\begin{array}{l}F: 0.111 \\
0.535\end{array}$ & $\begin{array}{l}F:-0.021 \\
0.905\end{array}$ & $\begin{array}{l}F: 0.060 \\
0.710\end{array}$ \\
\hline \multirow{3}{*}{$\begin{array}{l}\text { Nausea } \\
\text { in trans. } \\
\text { vehicles. } \\
\text { as a child }\end{array}$} & \multirow[t]{3}{*}{$\begin{array}{l}0.400^{*} \\
0.038\end{array}$} & $\begin{array}{l}\text { S: } 0.275 \\
0.136\end{array}$ & \begin{tabular}{|l|} 
S: $-0.389 *$ \\
0.028
\end{tabular} & $\begin{array}{l}\text { S:-0.188 } \\
0.292\end{array}$ & $\begin{array}{l}\text { S: } 0.091 \\
0.627\end{array}$ & $\begin{array}{l}\text { S: } 0.044 \\
0.819\end{array}$ & $\begin{array}{l}\text { S: } 0.030 \\
0.876\end{array}$ & $\begin{array}{l}\text { S: }-0.322 \\
0.072\end{array}$ & $\begin{array}{l}\text { S:-0.152 } \\
0.394\end{array}$ & $\begin{array}{l}\text { S: } 0.034 \\
0.834\end{array}$ \\
\hline & & $\begin{array}{l}\text { M: 0,357* } \\
0.047\end{array}$ & \begin{tabular}{l|} 
M: -0.292 \\
0.107
\end{tabular} & $\begin{array}{l}\text { M:-0.137 } \\
0.451\end{array}$ & $\begin{array}{l}\text { M: } 0.268 \\
0.154\end{array}$ & $\begin{array}{l}\text { M:-0.133 } \\
0.476\end{array}$ & $\begin{array}{l}\text { M: } 0.139 \\
0.464\end{array}$ & $\begin{array}{l}M:-0.277 \\
0.123\end{array}$ & $\begin{array}{l}\text { M:-0.136 } \\
0.446\end{array}$ & $\begin{array}{l}\text { M:-0.023 } \\
0.888\end{array}$ \\
\hline & & $\begin{array}{l}F:-0.013 \\
0.492\end{array}$ & $\begin{array}{l}\text { F: } \\
-0.392 * \\
0.027\end{array}$ & $\begin{array}{l}\text { F: }-0.376 * \\
0.035\end{array}$ & $\begin{array}{l}F: 0.317 \\
0.096\end{array}$ & $\begin{array}{l}F:-0.167 \\
0.380\end{array}$ & $\begin{array}{l}F:-0.152 \\
0.423\end{array}$ & $\begin{array}{l}F:-0.241 \\
0.179\end{array}$ & $\begin{array}{l}F:-0.141 \\
0.427\end{array}$ & $\begin{array}{l}F: 0.091 \\
0.577\end{array}$ \\
\hline
\end{tabular}

$\mathrm{S}=$ slow speed, $\mathrm{M}=$ medium speed, $\mathrm{F}=$ fast speed, ${ }^{* *} \mathrm{p}<0.01 ;{ }^{*} \mathrm{p}<0.05$ correlation coefficient 


\section{Conclusions}

In this research, we report on the results of a subjective study aimed at exploring how different navigation speeds set during "classic" movement through a VR environment will impact users in terms of cybersickness symptoms and stress levels. The used questionnaire consists of several general questions, and 11 related to experience in VR, derived by slightly modifying Kennedy's simulator sickness questionnaire. We also used the Pip biosensor stress measurement device as an objective measurement method. The results regarding the given questionnaire showed no statistically significant difference between navigation speeds related to physiological signs. Dominant symptoms indicated by participants at different speeds provide results that point to symptoms that may be explored in future research (such as vertigo, blurred vision, headache, and sweating). The stress measurement device did not give any statistically significant results with respect to relaxed, steady, and stress events across movement speeds, as well as compared to the neutral state recorded before the participant was immersed in the VR setting. Some interesting weak and moderate correlations were found between gender and stomach ache and need to vomit in fast speed, with female participants reporting the strongest experience of sickness symptoms (as also reported in some earlier studies, such as (Biocca, 1992; Stanney et al., 2003)). Age was found to have a positive correlation with vertigo in fast speed, and moderate positive correlation with nausea in transport vehicles. Our ongoing research is targeted towards further exploring cybersickness and locomotion methods in VR, expanding also by using other objective methods including behavioral and physiological measurements.

\section{References}

Baumgartner, T., Valko, L., Esslen, M. \& Jäncke, L. (2006) Neural Correlate of Spatial Presence in an Arousing and Noninteractive Virtual Reality: An EEG and Psychophysiology Study. CyberPsychology Behav. 9, 30-45. Available from: doi: 10.1089/cpb.2006.9.30 [Accessed 11th November 2019].

Biocca, F. (1992) Will Simulation Sickness Slow Down the Diffusion of Virtual Environment Technology? Presence Teleoperators Virtual Environ. 1, 334-343. Available from: doi: 10.1162/pres.1992.1.3.334 [Accessed 11th November 2019].

Brion, M. \& Pumudu, F. (2018) Early Prediction of Cybersickness in Virtual, Augmented \& Mixed Reality Applications: A Review. In: I2CT 2019: 5th International Conference for Convergence in Technology, I2CT 2019, 29-31 March 2018, Pune, Maharashtra, India. Croteam (2017) The Talos Principle VR . Available from:
URL http://www.croteam.com/talos-principle-vr/ [Accessed 11th November 2019].

Davis, S., Nesbitt, K. \& Nalivaiko, E. (2014) A Systematic Review of Cybersickness. In: IE 2014: Proceedings of the 2014 Conference on Interactive Entertainment, IE 2014, 2-3 December 2014, New York, USA, ACM Press. pp. 1-9. Available from: doi: 10.1145/2677758.2677780 [Accessed 11th November 2019].

Dennison, M.S., Wisti, A.Z. \& D'Zmura, M. (2016) Use of physiological signals to predict cybersickness. Displays. 44, 42-52. Available from: doi: 10.1016/j. displa.2016.07.002 [Accessed 11th November 2019].

Egan, D., Brennan, S., Barrett, J., Qiao, Y., Timmerer, C. \& Murray, N. (2016) An evaluation of Heart Rate and ElectroDermal Activity as an objective QoE evaluation method for immersive virtual reality environments. In: IEEE 2016: Eighth International Conference on Quality of Multimedia Experience (QOMEX), IEEE 2016, 6-8 June 2016, Lisabon, Portugal, IEEE. pp. 1-6. Available from: doi: 10.1109/QoMEX.2016.7498964 [Accessed 11th November 2019].

Golding, J.F. (2006) Predicting individual differences in motion sickness susceptibility by questionnaire. Pers. Individ. Dif. 41, 237-248. Available from: doi: 10.1016/j.paid.2006.01.012 [Accessed 11th November 2019].

Kelly, H.S. \& Stanney, K.M. (2015) Handbook of virtual environments: design, implementation, and applications. 2nd ed. Boca Raton, CRC Press; Taylor \& Francis Group.

Kennedy, R.S., Lane, N.E., Berbaum, K.S. \& Lilienthal, M.G. (1993) Simulator Sickness Questionnaire: An Enhanced Method for Quantifying Simulator Sickness. Int. J. Aviat. Psychol. 3, 203-220. Available from: doi: 10.1207/s15327108ijap0303_3 [Accessed 11th November 2019].

Keshavarz, B., Campos, J.L. \& Berti, S. (2015a) Vection lies in the brain of the beholder: EEG parameters as an objective measurement of vection. Front. Psychol. 6, 1-4. Available from: doi:10.3389/fpsyg.2015.01581 [Accessed 11th November 2019].

Keshavarz, B., Riecke, B.E., Hettinger, L.J. \& Campos, J.L. (2015b) Vection and visually induced motion sickness: How are they related? Front. Psychol. 6, 1-11. Available from: doi: 10.3389/fpsyg.2015.00472 [Accessed 11th November 2019].

McCauley, M.E. \& Sharkey, T.J. (1992) Cybersickness: Perception of Self-Motion in Virtual Environments. Presence Teleoperators Virtual Environ. 1, 311-318. Available from: doi: 10.1162/pres.1992.1.3.311 [Accessed 11th November 2019].

Medeiros, D., Cordeiro, E., Mendes, D., Sousa, M., Raposo, A., Ferreira, A. \& Jorge, J. (2016) Effects of speed and transitions on target-based travel techniques. In: VRST 2016:16. Proceedings of the 22nd ACM Conference on Virtual Reality Software and Technology, VRST '16, 2-4 November 2004, New York, 
USA, ACM Press. pp. 327-328. Available from: doi: 10.1145/2993369.2996348 [Accessed 11th November 2019].

Nichols, S., Cobb, S. \& Wilson, J.R. (1997) Health and Safety Implications of Virtual Environments: Measurement Issues. Presence Teleoperators Virtual Environ. 6, 667-675. Available from: doi: 10.1162/ pres.1997.6.6.667 [Accessed 11th November 2019].

Palmisano, S., Mursic, R. \& Kim, J. (2017) Vection and cybersickness generated by head-and-display motion in the Oculus Rift. Displays. 46, 1-8. Available from: doi: 10.1016/j.displa.2016.11.001 [Accessed 11th November 2019].

Rebenitsch, L. (2015) Managing cybersickness in virtual reality. ACM Crossroads. 22, 46-51. Available from: doi: 10.1145/2810054 [Accessed 11th November 2019].

Rebenitsch, L. \& Owen, C. (2016) Review on cybersickness in applications and visual displays. Virtual Real. 20, 101-125. Available from: doi:10.1007/s10055016-0285-9 [Accessed 11th November 2019].

So, R.H.Y., Lo, W.T. \& Ho, A.T.K. (2001) Effects of Navigation Speed on Motion Sickness Caused by an Immersive Virtual Environment. Hum. Factors J. Hum. Factors Ergon. Soc. 43, 452-461. Available from: doi: 10.1518/001872001775898223 [Accessed 11th November 2019].

Stanney, K.M., Hale, K.S., Nahmens, I. \& Kennedy, R.S. (2003) What to Expect from Immersive Virtual Environment Exposure: Influences of Gender, Body Mass Index, and Past Experience. Hum. Factors J. Hum. Factors Ergon. Soc. 45, 504-520. Available from: doi: 10.1518/hfes.45.3.504.27254 [Accessed 11th November 2019].

Stanney, K.M., Kennedy, R.S. \& Drexler, J.M. (1997) Cybersickness is Not Simulator Sickness. Proc. Hum. Factors
Ergon. Soc. Annu. Meet. 41, 1138-1142. Available from: doi: 10.1177/107118139704100292 [Accessed 11th November 2019].

Usoh, M., Catena, E., Arman, S. \& Slater, M. (2000) Using Presence Questionnaires in Reality. Presence Teleoperators Virtual Environ. 9, 497-503. Available from: doi: 10.1162/105474600566989 [Accessed 11th November 2019].

Wang, G. \& Suh, A. (2019) User Adaptation To Cybersickness In Virtual Reality: A Qualitative Study. In: ECIS 2019: Proceedings of the 27th European Conference on Information Systems, ECIS 2019, 7-13 June 2019. Stockholm \& Uppsala, Sweden. pp. 0-15.

Weech, S., Kenny, S. \& Barnett-Cowan, M. (2019) Presence and Cybersickness in Virtual Reality Are Negatively Related: A Review. Front. Psychol. 10, 1-19. Available from: doi: 10.3389/fpsyg. 2019.00158 [Accessed 11th November 2019].

Witmer, B.G. \& Singer, M.J. (1998) Measuring Presence in Virtual Environments: A Presence Questionnaire. Presence Teleoperators Virtual Environ. 7, 225-240. Available from: doi: 10.1162/105474698565686 [Accessed 11th November 2019].

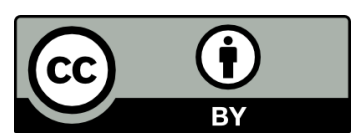

(C) 2020 Authors. Published by the University of Novi Sad, Faculty of Technical Sciences, Department of Graphic Engineering and Design. This article is an open access article distributed under the terms and conditions of the Creative Commons Attribution license 3.0 Serbia (http://creativecommons.org/licenses/by/3.0/rs/). 